\title{
Electrochemical Reduction of Bicarbonate on Carbon Nanotube-supported Silver Oxide: An Electrochemical Impedance Spectroscopy Study
}

\author{
Soraya Hosseini ${ }^{\mathrm{a},}$, Soorathep kheawhom ${ }^{\mathrm{a}}$, Salman Masoudi Soltani ${ }^{\mathrm{b}}$, Mohamed \\ Kheireddine Aroua ${ }^{\mathrm{C}}$ \\ ${ }^{a}$ Computational Process Engineering Research Laboratory, Department of Chemical Engineering, \\ Faculty of Engineering, Chulalongkorn University, Bangkok 10330, Thailand \\ ${ }^{b}$ Department of Mechanical, Aerospace \& Civil Engineering, College of Engineering, Design and Physical \\ Sciences, Brunel University London, London UB8 3PH, United Kingdom

 \\ Sunway University, Bandar Sunway, 47500, Petaling Jaya, Malaysia \\ *Corresponding author's Tel: +60176515750 \\ *Corresponding author‘s e-mail: soraya20h@gmail.com
}

\begin{abstract}
Bicarbonate reduction on a silver-oxide $\left(\mathrm{Ag}_{2} \mathrm{O}\right)$-based electrode was studied via cyclic voltammetry and electrochemical impedance spectroscopy techniques. The effects of electrode composition, electrolyte concentration and the scan rate $(10-250 \mathrm{mV} / \mathrm{s})$ were investigated at a temperature of $27^{\circ} \mathrm{C}$. An optimum mass ratio of 70/30 ( $\left.\mathrm{Ag}_{2} \mathrm{O} / \mathrm{CNT}\right)$ led to a maximum current density of $83 \mathrm{mAcm}^{-2}$ at $-0.43 \mathrm{~V}$ (VS Ag/AgCl). At scan rates between 10 to $250 \mathrm{mV} / \mathrm{s}$, a negative shift with a displacement of around $1.032 \mathrm{~V}$ was observed indicating the presence of irreversible reduction reactions. The observed irreversibility suggested that the reaction mechanism can be described by both diffusion and adsorption phenomena. The standard heterogeneous rate constant $\left(k_{o}\right)$ and the formal redox potential $\left(E_{o}\right)$ were found to be $1.51 \times 10^{-4} \mathrm{~cm} / \mathrm{s}$ and $1.218 \mathrm{~V}$, respectively. The EIS results confirmed the formation of the inductive loops at reduction potentials - a consequence of the adsorption of the generated species. A reduction in charge transfer resistance and a continual drop in the potential from -0.1 down to $-1.4 \mathrm{~V}$ was also observed. This was accompanied by $\mathrm{H}_{2}$ evolution
\end{abstract}


and bicarbonate production. The calculated pKa value of 10.20 upon the completion of the bicarbonate reduction reactions, confirmed the conversion of bicarbonate to carbonate ions.

Key words: Silver oxide; Bicarbonate; Electrochemical reduction; Impedance spectroscopy

\section{Introduction}

Carbon dioxide $\left(\mathrm{CO}_{2}\right)$ emissions from fossil fuel-fired power plants (e.g. coal, natural gas and oil), transportation, industry and residential are the key contributors to greenhouse gas (GHG) emissions [1]. The United States is accounted for around $14.69 \%$ of global $\mathrm{CO}_{2}$ emissions as the primary greenhouse gas after China - the biggest emitter of carbon dioxide at around (23.4\%) [2]. The increased release of GHG, and particularly $\mathrm{CO}_{2}$, has led to the progressive climate change and global warming and has caused serious environmental damages including polar melting, ocean acidification, melting glaciers, rising sea levels (coastal erosion and flooding of low-lying land and cities), increasing the severity of tropical storms and human health. Various strategies have been suggested and tried in order to mitigate $\mathrm{CO}_{2}$ emission. These include the improvement of fuel efficiency of cars, utilization of renewable energy resources (solar, wind and wave power), enhancement of energy efficiency in buildings and carbon capture and sequestration (CCS). However, a tangible emission reduction could be only achieved with the help of the development of novel and more energyefficient processes [3-5].

Recycling $\mathrm{CO}_{2}$ into readily-transportable hydrocarbon fuels and valuable chemicals via photochemical, biochemical and electrochemical reduction methods, has increasingly gained attention as a solution to both the energy and environmental challenges of the world today [6, 7]. Moreover, electrochemical reduction is a promising method, due to its operability under ambient reaction conditions and the ease of process control. In addition, unlike photochemical and biochemical processes, less limitation is associated with the 
electrochemical reduction technologies in converting $\mathrm{CO}_{2}$ into value-added chemicals. Universally, the core research goal has been centred on the improvement of the process efficiency and product yield $[8,9]$. The $\mathrm{CO}_{2}$ reduction process is initiated in large negative potentials and generates C-intermediates that are thermodynamically unstable. Hydrogen evolution, as a competitive reaction, can be promoted in $\mathrm{CO}_{2}$ electrochemical in an aqueous electrolyte via the utilization of a large negative potential. Therefore, development of novel electrocatalysts is vital in order to control and improve product selectivity $[10,11]$.

Different catalytic metals have been used in the production of various fuels and hydrocarbons via electrochemical reduction of $\mathrm{CO}_{2}$. Several studies have demonstrated that some catalysts such as silver (Ag), gold (Au), copper $(\mathrm{Cu})$ and zinc $(\mathrm{Zn})$ are able to co-produce $\mathrm{CO}$ and $\mathrm{H}_{2}$. However, Ag and Au are more selective towards the production of CO [12]. This product (i.e. $\mathrm{CO}$ and $\mathrm{H}_{2}$ - known as syngas) can then be converted into liquid fuels via the well-known Fischer-Tropsch process [13]. Some earlier works have studied the effect of an Ag-based cathode to generate $\mathrm{CO}$ via $\mathrm{CO}_{2}$ reduction. It has been reported that silver-based catalysts correspond to a higher CO selectivity due to the weak binding energies of $\mathrm{CO}$ on the catalyst's surface. Hoshi et al. 1997 studied the electrochemical reduction of $\mathrm{CO}_{2}$ on puremetal crystals: Ag (100), Ag (110) and Ag (111). In these studies, a higher current density was observed for Ag (110) as compared to Ag (111) and Ag (100) [14]. Several electrocatalysts including Ag bulk [15], immobilized Ag [16], Ag-nanoparticles [17], roughened Ag surface [18], bimetallic alloy Ag/Au [19], Ag/TiO2 [20] and Ag/graphene [21] have also been reported for $\mathrm{CO}_{2}$ reduction, with $\mathrm{CO}$ and $\mathrm{H}_{2}$ as the main products. $\mathrm{CO}$ is generally adsorbs weakly on Ag and is hardly detected by vibrational spectroscopy [22]. Electrochemical reduction of $\mathrm{CO}_{2}$ to $\mathrm{CO}$ on polycrystalline silver was greatly improved using a thin $\mathrm{Ag}_{2} \mathrm{O}$ upon an anodization treatment [23]. $\mathrm{Ag}_{2} \mathrm{O}$ with carbonic materials as electrode has been used in several applications e.g. as supercapacitors [24], as photocatalyst for the 
degradation of acidic dyes and bacterial inactivation [25], in zinc-silver batteries [26] and in sensors for the detection of vitamin B2, B6 and ascorbic acid [27].

This paper investigates the efficiency of a silver oxide-based electrode, supported on carbon nanotube, in measuring the degree of bicarbonate reduction. The prepared electrode can also be used as a sensor in renal electrolyte $\left(\mathrm{NaHCO}_{3}, \mathrm{KHCO}_{3}\right)$ excretion in humans. This work therefore, entails the development and characterization of a composite $\mathrm{Ag}_{2} \mathrm{O} / \mathrm{CNT}$ electrode and its application in electrochemical bicarbonate reduction. The composite electrode was developed using different current collectors. A uniform particle size distribution was observed for the prepared solution, containing $\mathrm{Ag}_{2} \mathrm{O}$, carbon nanotube, nafion (5\%) and isopropanol. The current collectors (e.g. copper sheet, graphite rod and glassy carbon electrode) were painted using the prepared solution. The effects of catalyst loading (30 to 100 $\mathrm{mg})$, electrolyte concentration $(0.1$ to $1 \mathrm{M})$ and scan rate $(10-250 \mathrm{~m} / \mathrm{s})$ on the efficiency of the process were investigated and the activity of the $\mathrm{Ag}_{2} \mathrm{O} / \mathrm{CNT}$ electrode was compared against that of pure $\mathrm{Ag}_{2} \mathrm{O}$ electrode. In our experiments, $\mathrm{NaHCO}_{3}$ was directly used as the $\mathrm{CO}_{2}$ source. In order to investigate the electrode/electrolyte interface behaviour, electrochemical impedance spectroscopy (EIS) measurements were employed (open circuit potentials) to further evaluate the electrochemical behaviour of the sodium hydrogen carbonate and composite electrodes (200 kHz to $100 \mathrm{~Hz}$ ).

\section{Experimental}

\subsection{Chemicals \& Materials}

Sodium hydrogen carbonate (99.9\%), $\mathrm{H}_{2} \mathrm{SO}_{4}$ (97\%) and isopropanol (absolute, 99.5\%) were all purchased from a local company. $\mathrm{Ag}_{2} \mathrm{O}$ (99.9\%) and Nafion solution (5 wt\% - dispersed in water) were supplied by Sigma-Aldrich. Multiwalled carbon nanotube $(20-30 \mathrm{~nm}$ in diameter, $0.5-2 \mu \mathrm{m}$ in length, $>95 \%$ pure) was purchased from Nanostructured \& 
Amorphous Materials. Copper sheets were made available by a local market. All chemicals were used without any further purification. Electrolyte solutions were prepared using ultrapure deionized water.

\subsection{Electrode Preparation}

All experiments were conducted in an electrochemical cell, equipped with three electrodes at room temperature $\left(27{ }^{\circ} \mathrm{C}\right)$ and under the ambient pressure. Cyclic voltammetry $(\mathrm{CV})$ experiments were carried out using an Autolab Metrohm potentiostat electrochemical workstation. The electrocatalytic activity of the $\mathrm{Ag}_{2} \mathrm{O} / \mathrm{CNT}$ as the working electrode was measured via cyclic voltammetry at a potential scan rate of $50 \mathrm{mV} / \mathrm{s}(1$ to $-2 \mathrm{~V})$. An aqueous solution of $\mathrm{NaHCO}_{3}(100 \mathrm{~mL})$ was used as the electrolyte. The current density was determined based on the geometrical area (A) of the electrode. The $\mathrm{Ag}_{2} \mathrm{O} / \mathrm{CNT}$ ink and the pure $\mathrm{Ag}_{2} \mathrm{O}$ were used on different current collectors to act as the working electrode $(\mathrm{A}=1.6$ $\mathrm{cm}^{-2}$ ). A platinum (Pt) wire and an $\mathrm{Ag} / \mathrm{AgCl}$ (sat. $\mathrm{KCl}$ ) were employed as the counter electrode and the reference electrode, respectively. The $\mathrm{Ag}_{2} \mathrm{O} / \mathrm{CNT}$ ink, containing $\mathrm{Ag}_{2} \mathrm{O}$, carbon nanotube, organic binder Nafion (5\%) and isopropanol, was painted on the current collectors. Nafion (5\%) was added only as a binder to sustain the mechanical integrity and was not expected to have a major impact on the activity of the electrode under the electrochemical reactions. Initially, $\mathrm{Ag}_{2} \mathrm{O}(80 \mathrm{mg})$ was added to isopropanol (5 mL). The mixture was then ultrasonically agitated for $30 \mathrm{~min}$. Nafion $(5 \mu \mathrm{L})$ and carbon nanotube (20 mg) were next added and the resulting mixture was further sonicated for 30 min to ensure adequate dispersion. For electrochemical testing, the mixture was painted on various current collectors such as copper sheet, graphite rod and glassy-carbon electrode. The painted sheets (area $=1.6 \mathrm{~cm}^{2}$ ) were then dried under the ambient air to serve as the working electrode. Sodium bicarbonate $\left(\mathrm{NaHCO}_{3}\right)$ was used as the $\mathrm{CO}_{2}$ source. The electrochemical impedance spectroscopy (EIS) measurements were conducted in frequency ranges of $200 \mathrm{kHz}-100 \mathrm{~Hz}$ 
using the potentiostat (Alpha Analytical SP-300 with EC-Lab V10.12 software). The titration method via a Titrino Plus was carried out using $\mathrm{H}_{2} \mathrm{SO}_{4}(0.1 \mathrm{M})$.

\section{Results \& Discussion}

\subsection{Electrochemical Reduction of Bicarbonate}

This work describes the development and characterization of a novel $\mathrm{Ag}_{2} \mathrm{O} / \mathrm{CNT}$ composite electrode and its application in electrochemical reduction of bicarbonate. Three different electrodes were used with copper sheet, graphite rod and glassy carbon as the current collectors. The reduction reaction was carried out in a bicarbonate solution (i.e. the $\mathrm{CO}_{2}$ source). The $\mathrm{Ag}_{2} \mathrm{O} / \mathrm{CNT}$ electrode (80/20 mass ratio) was used throughout the experiments to identify the optimum current collector based on the product selectivity. The electrochemical behaviour of the $\mathrm{Ag}_{2} \mathrm{O} / \mathrm{CNT}$ electrode with different metal loadings (30, 50, 70 and $100 \mathrm{mg}$ ) was studied through cyclic voltammetry (a standard three-electrode configuration). The effect of the scan rate was studied in order to investigate the reduction mechanism of bicarbonate on the composite electrode (10 to $250 \mathrm{mV} / \mathrm{s}$ ). The bicarbonate concentration was varied from 0.1 to $1 \mathrm{M} \mathrm{NaHCO}$.

Figure 1 shows the comparison between the three current collectors that were coated using the $\mathrm{Ag}_{2} \mathrm{O} / \mathrm{CNT}$ ink. Current collectors are the critical segments of electrodes and are responsible for efficient charge transport to the active electrode material. It can be seen that the current density of the copper sheet collector is higher than those of the glassy carbon and the graphite-rod collectors. EIS measurements were conducted to compare electron transfer in copper sheet, glassy carbon and graphite rod in $\mathrm{NaKHCO}_{3}(0.5 \mathrm{M})$. It is observed that the resistance of the copper sheet and glassy carbon are much lower than that of the graphite rod, indicating a smaller resistance and a facilitated electrical transportation for the course of the electrochemical reactions. The reduction peak (copper sheet) is broader due to the increased 
charge transfer (Fig. 1). The CV curves exhibit a single broad cathodic peak reduction around $-0.43 \mathrm{~V}$ during the reverse scan i.e. the reduction of bicarbonate ions and evolution of hydrogen. No extra peak can be observed and only promote bicarbonate reduction and $\mathrm{H}_{2}$ production with $\mathrm{Ag}_{2} \mathrm{O} / \mathrm{CNT}$.

Four sets of $\mathrm{Ag}_{2} \mathrm{O} / \mathrm{CNT}$ compositions were prepared (Table 1). The electrodes were fabricated by airbrushing a catalytic ink over the current collector (i.e. the copper sheet). In all cases, the samples were cycled between $-2.0 \mathrm{~V}$ and $1.0 \mathrm{~V}$ at a scan rate of $50 \mathrm{mV} / \mathrm{s}$. Figure 2 shows the corresponding cyclic voltammetry results, measured for different metal loadings (i.e. 30, 50, 70,100 mg), deposited on the copper sheet (as described previously in the experimental section). The Y-axis corresponds to the ratio between the current and the geometric area of the electrode (A). Cyclic voltammetry experiments revealed that the adsorption of bicarbonate species on the $\mathrm{Ag}_{2} \mathrm{O} / \mathrm{CNT}$ electrode takes place at similar potentials. A reduction, however, was observed between -2.0 and $1.0 \mathrm{~V}$ - depending on catalyst loading. No oxidation peak was observed, suggesting the reduction of bicarbonate ions on the working electrode surface to carbonate ions or other valuable chemicals. The formation of formic acid (formate) was observed at a voltage of $-0.41 \mathrm{~V}$. The results show that the anodic contributions are between 0 and $1.0 \mathrm{~V}$, while the cathodic counterparts appear to be between 0 and $-2.0 \mathrm{~V}$. On the cathodic end of the CVs $(-1.2 \mathrm{~V})$, an increase in the absolute current value can be observed. The sharp reduction is associated with the $\mathrm{H}_{2}$ evolution. The cyclic voltammogram shows an increase in the reduction peaks associated with the $\mathrm{Ag}_{2} \mathrm{O} / \mathrm{CNT}$ composite-coated copper sheet when the catalyst loading was increased from $30 \mathrm{mg}$ to $70 \mathrm{mg}$. It can be easily learnt that the best performance with regards to the reduction reaction is obtained with the copper sheet, coated with $\mathrm{Ag}_{2} \mathrm{O} / \mathrm{CNT}$ (70/30 mass) (Figure 2). The $\mathrm{Ag}_{2} \mathrm{O}$ loading considerably affects the electrocatalytic properties. However, no significant electrocatalytic deviation can be observed with a 30 -mg loading of the metal 
oxide. It is seen that the CV curves corresponding to the copper sheet coated with $\mathrm{Ag}_{2} \mathrm{O} / \mathrm{CNT}$ with different catalyst loadings are similar; a reduction peak can be clearly observed for all the $\mathrm{Ag}_{2} \mathrm{O} / \mathrm{CNT}$ electrodes (Figure 2). In addition, the peaks become broader with an increase in the amount of catalyst used, indicating an enhanced kinetic process with the $\mathrm{Ag}_{2} \mathrm{O} / \mathrm{CNT}$ composite electrode. No reduction peak was revealed with the bare copper sheet. However, the current density of the copper sheet increased to 15,48 and $83 \mathrm{~mA} / \mathrm{cm}^{2}$, when loaded with 30, 50 and $70 \mathrm{mg} \mathrm{Ag}_{2} \mathrm{O}$, respectively. It is worth noting that despite what one would expect from increasing the metal loading (from 30 to $70 \mathrm{mg} \mathrm{Ag} 2 \mathrm{O}$ ), the activity did not follow a similar trend. This suggests that the CNT loading did also affect the resulting electrocatalytic activity and the electron conductivity. The results show that the accessible surface area is not proportional to the corresponding metal loading. This is important as the resulting activity is often a function of the actual active surface area. Therefore, for high loadings (i.e. pure metal), the $\mathrm{Ag}_{2} \mathrm{O}$ particles could be agglomerated and thus, result in a decrease in the total active surface area of the electrode (Figure 3). The appearance of the reduction peak (-0.43 V) follows a similar trend to that of the oxidation peak at positive potentials. The CV curves indicate that the $\mathrm{Ag}_{2} \mathrm{O} / \mathrm{CNT}$ composite and the pure $\mathrm{Ag}_{2} \mathrm{O}$ are both active for the reduction reactions in the $\mathrm{NaHCO}_{3}$ solution. The pure $\mathrm{Ag}_{2} \mathrm{O}$ demonstrates an oxidation peak $(0.8 \mathrm{~V})$ which could correspond to the formation of AgO in the $\mathrm{NaHCO}_{3}$ solution. Wan et al. (2013) studied the effect of electrochemical parameters on the formation and reduction of silver oxides. They reported two oxidation peaks i.e. at 0.26 and $0.57 \mathrm{~V}$ vs SCE, corresponding to the formation of $\mathrm{Ag}_{2} \mathrm{O}$ and $\mathrm{AgO}$ in an $\mathrm{NaOH}$ solution. The current density of the electrode based on pure $\mathrm{Ag}_{2} \mathrm{O}$ reveals a lower performance than that of the $\mathrm{Ag}_{2} \mathrm{O} / \mathrm{CNT}$ (50/50). This is due to the enhanced dispersion of the catalyst within the carbon nanotube network, leading to an improved electrical conductivity. 
With a diluted bicarbonate solution, the $\mathrm{CV}$ analysis for the $\mathrm{Ag}_{2} \mathrm{O} / \mathrm{CNT}$ composite-coated copper sheet shows little hysteresis at a reduction potential close to $-0.43 \mathrm{~V}$. Figure 4 illustrates the effect of bicarbonate concentration ( 0.1 to $1 \mathrm{M} \mathrm{NaHCO}$ ) on the reduction process. It is seen that with a $0.1 \mathrm{M} \mathrm{NaHCO}_{3}$ solution, a smaller area of the $\mathrm{CV}$ curve is obtained. The difference can be linked to the lower conductivity of the $0.1 \mathrm{M} \mathrm{NaHCO}_{3}$ solutions and diffusion limitations in the pores of the composite electrodes. The larger CV areas are associated with the presence of concentrated bicarbonate ions. This means that the electrochemically-active surface areas consume more bicarbonate ions and thus, increase the current density. In this experiment, even in a low concentration of bicarbonate ions, the reduction peak is observed during the reduction reaction when using the $\mathrm{Ag}_{2} \mathrm{O} / \mathrm{CNT}$ composite electrode. It can be seen that the reduction peak current shifts towards smaller potentials with an increase in the bicarbonate concentration. With $0.1 \mathrm{M} \mathrm{NaHCO}$, bicarbonate ions are present at a lower concentration. The distribution of the bicarbonate ions, close to the electrode surface, is initially uniform; a current started to develop as a consequence of the reduction reactions. The current density is proportional to the surface concentration with an intercept equal to zero. Plotting $i_{c}$ versus $C_{0}$, reveals a linear segment which would not passes through the origin. A large deviation due to a non-zero intercept suggests the presence of adsorbed species. The linear relation between $i_{c}$ versus $C_{o}$, follows equation (1) for an irreversible reduction process [28]:

$i_{c}=\left(2.99 \times 10^{5}\right) A \alpha^{0.5} v^{0.5} D_{0}^{0.5} C_{0}$

where $i_{c}$ is the peak current $(\mathrm{mA}), \alpha$ is the electron transfer coefficient, $\mathrm{D}_{0}$ is the diffusion coefficient $\left(\mathrm{cm}^{2} / \mathrm{s}\right)$ and $C_{o}$ is concentration $\left(\mathrm{mol} / \mathrm{cm}^{3}\right)$, A is the surface area $\left(\mathrm{cm}^{2}\right)$ and $\mathrm{v}$ is the scan rate $(\mathrm{mV} / \mathrm{s})$.

The linear relation between $i_{c}$ versus $C_{o}$ follows the equation:

$i_{c}=387.95 C-69.318\left(R^{2}=0.984\right)$ 
To further conceptualize the charge transfer, the CV curves for the Ag2 O/CNT composite electrode were obtained at various scan rates (10 to $250 \mathrm{mV} / \mathrm{s}$ ) in a $0.5 \mathrm{M} \mathrm{NaHCO}_{3}$ solution (Fig. 5). It is observed that with an increase in the scan rate, the peak current linearly increases. Figure 5 shows the varying baseline (cathodic peaks) as a function of the scan rate (10 to $250 \mathrm{mV} / \mathrm{s}$ ). However, the anodic peaks are less dependent on the scan rate. The cathodic peaks can be split into three distinct regions: charge transfer regions, diffusioncontrolled regions and mixed charge transfer-diffusion controlled regions [29]. The cathodic peak current is proportional to the square root of the scan rate according to equation 1 . The plot of $i_{c}$ vs. $\mathrm{V}^{0.5}$ is useful in the characterization of the electrochemical reduction reaction (equation 3). The peak currents increase linearly as a function of the square root of the scan rate for irreversible electron transfers.

$i_{c}=-50.166 v^{0.5}-5.437\left(R^{2}=0.9665\right)$

The logarithm of the cathodic peak current $\left(i_{p}\right)$ versus the logarithm of the scan rate $(v)$ is linear $(10 \mathrm{mV} / \mathrm{s}<$ scan rate $<250 \mathrm{mV} / \mathrm{s})$ :

$\log i_{c}=0.3419 \log v+3.8547\left(R^{2}=0.9544\right)$

The slope (i.e. 0.3419) is different from the theoretically-expected value of 0.5 for diffusioncontrolled processes. These findings indicate that for the studied potentials, the process is not fully diffusion-controlled when using the $\mathrm{Ag}_{2} \mathrm{O} / \mathrm{CNT}$ electrode. The reduction peak shifts towards the larger negative potentials with an increase in the scan rate from 10 to $250 \mathrm{mV} / \mathrm{s}$. At slower scan rates, a noticeable time interval between the oxidation and reduction processes was observed (two peaks). However, at higher scan rates, a different behaviour was observed during the cathodic process: the two cathodic peaks merged into a single peak due to the adsorption of the reactants. Potential $\left(\mathrm{E}_{\mathrm{p}}\right)$ for an irreversible process is calculated by (Laviron [30]) :

$E_{p}=E_{o}-\frac{R T}{\alpha F}\left[0.78+2.303 \log \left(\frac{\left(a F D_{o}\right)^{0.5}}{K^{o}(R T)^{0.5}}\right)\right]-\frac{2.303 R T}{\alpha F} \log v^{0.5}$ 
where $\alpha$ is the transfer coefficient, $k^{o}$ is the standard heterogeneous rate constant of the reaction, $D_{o}$ is diffusion coefficient, $v$ the scan rate and $E_{o}$ is the formal redox potential. By plotting potential $E_{p}$ versus $\log v^{0.5}$, the transfer coefficient $(\alpha)$ can be calculated from the slope of the resulted plot:

$E_{p}=-2.0681 \log v^{0.5}-2.401\left(r^{2}=0.8904\right)$

$E_{p}$ is a function of the scan rate, shifting towards the negative direction for reduction by an amount of $1.032 \mathrm{~V}$ from equation $1.15 \mathrm{RT} / \alpha \mathrm{F}$ [28] i.e. $20 \%$ smaller than the experimentallyobtained data $(1.221 \mathrm{~V})$ for scan rates between 10 and $250 \mathrm{mV} / \mathrm{s}$. The two parameters, $\mathrm{k}^{0}$ $\left(1.51 \times 10^{-4} \mathrm{~cm} / \mathrm{s}\right)$ and $E_{o}(1.218 \mathrm{~V})$, can be estimated from the intercept of the plot via nonlinear regression.

Chronoamperometry techniques were employed to estimate the electrochemically-active surface areas of the $\mathrm{Ag}_{2} \mathrm{O} / \mathrm{CNT}$ (70/30\%) electrode. To measure the electrochemically-active surface areas of the electrode, the chronoamprogram of $0.1 \mathrm{M} \mathrm{KH}_{2} \mathrm{PO}_{4}$ solution, containing 5 $\mathrm{mM}$ of $\mathrm{K} 4 \mathrm{Fe}(\mathrm{CN})_{6}$ as the redox probe, was recorded. The electrochemical experiments with the composite electrode were performed in an Autolab Metrohm potentiostat, equipped with NOVA 1.10 software. In the chronoamperometric studies, the current for the electrochemical reaction of ferrocyanide, diffusing to an electrode surface, is calculated as (Cottrell equation [31]):

$I_{=} \frac{n F A D^{1 / 2} C_{O}}{(\pi t)^{1 / 2}}$

where I is the current (A), $n$ is number of electrons, A is the active area of electrode $\left(\mathrm{cm}^{2}\right), D$ and $C_{0}$ are the diffusion coefficient $\left(6.20 \times 10^{-6} \mathrm{~cm}^{2} / \mathrm{s}\right)$ and bulk concentration of $\mathrm{K} 4 \mathrm{Fe}(\mathrm{CN}) 6$ $\left(5 \times 10^{-6} \mathrm{~mol} / \mathrm{cm}^{3}\right)$, respectively, $\mathrm{F}$ is the Faraday constant $(96.487 \mathrm{C} / \mathrm{mol})$; while the remaining parameters have their usual meanings.

For a diffusion-controlled process, the $I$ vs $t^{-1 / 2}$ plot is linear and from the slope, the value for A can be calculated. In our study, a value of $1.935 \mathrm{~cm}^{2}$ was obtained by plotting $I$ vs $t^{-1 / 2}$ - 
which is larger than the geometric surface area (i.e. $1.6 \mathrm{~cm}^{2}$ ). This could be due to the porosity of the electrode surface.

\subsection{Electrochemical Impedance Spectroscopy Studies}

Electrochemical Impedance Spectroscopy (EIS) studies were done in order to compare the electrical conductivity and charge transfer resistance of the $\mathrm{Ag}_{2} \mathrm{O} / \mathrm{CNT}$ composite electrode. The Nyquist plots of substrates and the composite electrode - with a sine wave of $10 \mathrm{mV}$ amplitude over a frequency range of $200 \mathrm{kHz}$ to $100 \mathrm{~Hz}$ - are shown in Fig. 6, 7 and 8. Each EIS experiment was carried out at a constant voltage for a broad range of voltages (-2.0 to 0.1 V). Nyquist impedance plots for the substrates i.e. the copper sheet, glassy carbon and graphite rod in $0.5 \mathrm{M} \mathrm{NaHCO}_{3}$ at a potential of $0.0 \mathrm{~V}$ were also investigated (not shown). In the 0.5 $\mathrm{M} \mathrm{NaHCO}_{3}$ solution and at high frequencies, a half-circle (i.e. and arc) is observed on the Nyquist plot, corresponding to the electron transfer process. However, at low frequencies, a linear segment is formed which corresponds to the diffusion-controlled process. The graphite rod shows a half-circle which has the largest diameter compared to the plots for the other two substrates. The copper sheet corresponds to a plot with the smallest arc diameter. With the copper sheet used as the substrate, regardless of the electrode, the electron transfer process is immediate and the electrochemical response is nearly a straight line.

Figures 6a and b show the Nyquist plot for the copper sheet in $0.5 \mathrm{M} \mathrm{NaHCO}_{3}(-1.2$ to 1.0 V). The plot demonstrates some specific features: there is a fall in the size of impedance spectrum as the potential increases. The impedance arcs $(0.1$ to $0.7 \mathrm{~V}$, all located in the first quadrant) decreased varyingly with an increase in the potential; the resistance slightly drops as well. The impedance arcs (0.8 to $1 \mathrm{~V})$ are in the first and fourth quadrants. This suggests that an inductive event has occurred at the end of the oxidation reaction. Fig.6b depicts the plots for the impedance arcs in the reduction reaction $(-0.1$ to $-1 \mathrm{~V})$. The diameters of the impedance arcs have significantly increased. These arcs are all located in the fourth quadrant 
for higher frequencies with the sloping lines visible at lower frequencies. By reducing the potential, the impedance plots are wrapped around the X-axis (anti-clockwise) and the capacitive arcs are flipped to the fourth quadrant (the real component of the impedance is negative). A decrease in the slope of the lines is observed as the potential increases from -0.1 to $-1 \mathrm{~V}$, indicating the presence of reaction species as a result of the reduction reaction and the electron-transfer. A voltage of $-0.3 \mathrm{~V}$ is typically required for $\mathrm{H}_{2}$ to evolve [10]. The second pathway is a conversion of bicarbonate which occurs at a voltage of $-0.43 \mathrm{~V}$. The Nyquist plots in the potential zone from -0.1 to $-1 \mathrm{~V}$ show the inductive phenomenon at low frequencies. This is an indication of inductance in the system. The inductive features depend on the applied potential and the presence of $\mathrm{CO}$ on the electrode surface. CO has a very short lifetime due to the interaction with the free metal electrons [32]. The EIS responses at high frequency ( 0.8 to $1 \mathrm{~V}$ ) display an inductive behaviour in the potential range (reduction) during which the electrons are injected into the electrode (Fig. 6a). Another pathway opens up the hydrocarbon formation (directly from the CO generation) that is promoted at $-0.8 \mathrm{~V}$ with copper [33]. At lower potentials (-1 V), arcs with higher diameters appear. This is linked to the generation of various products from bicarbonate reduction and $\mathrm{H}_{2}$ evolution with the copper sheet used as the electrode.

Figures 7a and b show the EIS spectra of $\mathrm{Ag}_{2} \mathrm{O} / \mathrm{CNT}$ (70/30\%)-coated copper sheet in a 0.5 $\mathrm{M} \mathrm{NaHCO}$ solution (-1.2 to $1 \mathrm{~V}$ ). All the EIS curves comprise a half-circle in the highfrequency region and a linear segment in the low frequency area (Figure 7). The half-circle is explained via the charge transfer resistance throughout the bicarbonate ion reaction at the interface of the electrolyte and the composite electrode. The linear section represents the retardance characteristic of the composite electrode and can be linked to the ion-diffusion processes in the electrode. The diffusion/transport of ions within the pores or surface roughness of the composite electrode during the reduction reaction affects the shape of the 
line. Figure 7a demonstrates the EIS spectra for the oxidation of the $\mathrm{Ag}_{2} \mathrm{O} / \mathrm{CNT}$ electrode (0.1 to $1 \mathrm{~V})$. The EIS studies show that the diameters of the arcs on the Nyquist plots slightly decrease with an increase in the potential (0.1 to $1 \mathrm{~V})$. A Randles circuit was used in order to model the EIS data. The circuit parameters were estimated using the Z-Fit software. The randomized/simplex fitting method was used to identify the best fit for the model and the experimentally-measured data (Table 2). Figure 7b shows the fitted circuit comprising resistance, capacitance, constant phase element and the Warburg diffusion resistance. The half-circle is associated with the resistance and capacitance elements in parallel.

Figure 8a shows the reduction-based EIS measurements (-0.1 to $-0.9 \mathrm{~V}$ ) where the diameter of the half-circle decreases with a reduction in the potential. Changing the potential has a direct impact on the charge transfer resistance of the composite electrode. The reduction reactions in the bicarbonate solution could decrease the charge transfer resistance at the $\mathrm{Ag}_{2} \mathrm{O} / \mathrm{CNT}$ interface. The reduction reaction takes place at a potential of $-0.43 \mathrm{~V}$. This is due to the catalytic reaction of $\mathrm{HCO}_{3}{ }^{-}$and the transfer of the proton-electron pair $\left(\mathrm{H}^{+}+\mathrm{e}^{-}\right)$to the composite electrode. The arcs begin to bend and the negative value of the faradaic impedance points out to an inductive event. Inductive loops have been ascribed to electrochemical asymmetries, which are observed within the studied range of potentials. Some hypotheses have been proposed in the literature to explain this phenomenon, including the heterogeneity of the ions distribution inside the electrode to generate concentration cells between different particles of electrode or the phase change of the active material during the EIS measurement [34]. The charge transfer resistance is further decreased by reducing the potential to $-1.4 \mathrm{~V}$. The diameter of the half-circle for $\mathrm{Ag}_{2} \mathrm{O} / \mathrm{CNT}$ plot at $-0.9 \mathrm{~V}$ is much smaller than at $-0.3 \mathrm{~V}$ or $-0.1 \mathrm{~V}$ potentials (Fig.8a). The semi-circle disappears at potentials above $-1 \mathrm{~V}$. The change in the half-circle diameter is the consequence of the variation in the interfacial resistance for the electron transfer from the bicarbonate solution to the electrode surface. The arc gradually 
shrinks with an increase in potential $(-0.1 \mathrm{~V}$ to $-1.2 \mathrm{~V})$, indicating the completion of the bicarbonate reduction reactions and $\mathrm{H}_{2}$ evolution. A decrease in the charge transfer resistance is observed when the potential drops from -0.1 to $-1.4 \mathrm{~V}$. Figure $8 \mathrm{~b}$ shows a circuit, comprising resistance, capacitance, constant phase element, Warburg diffusion resistance and inductance. The inductance has been included in the circuit due to the inductance phenomenon (Figure 7b). The charge transfer resistance decreases to around $1 \Omega$ while the capacitance increases, owing to the reduced thickness of the interfacial layer. The cycling performance was investigated in order to test the stability of the electrode/electrolyte over 30 cycles. The results confirm a good stability without any fluctuation.

\subsection{Bicarbonate Conversion Studies}

Bicarbonate $\left(\mathrm{HCO}_{3}{ }^{-}\right)$and carbonate $\left(\mathrm{CO}_{3}{ }^{2-}\right)$ are defined as the mono and dibasic forms of carbonic acid $\left(\mathrm{H}_{2} \mathrm{CO}_{3}\right)$ with $\mathrm{Pk}_{1}$ and $\mathrm{Pk}_{2}$ values of 6.35 and 10.33 in water, respectively. Both compounds can be used in $\mathrm{pH}$-jump experiments; from an alkaline $\mathrm{pH}$ to a physiological $\mathrm{pH}$. The result of the CV studies show that a cathodic reduction peak appears in bicarbonate solution $(-0.43 \mathrm{~V})$ for a $\mathrm{pH}$ of around 7.3. The reduction peak is attributed to the aqueous bicarbonate ions which could be reduced on the surface of the electrode. Different kinds of species are typically formed in bicarbonate solutions (Fig. 9) [35].

In water and depending on the $\mathrm{pH}, \mathrm{NaHCO}_{3}$ is ionised to hydroxide $\left(\mathrm{OH}^{-}\right)$, bicarbonate $\left(\mathrm{HCO}_{3}{ }^{-}\right)$and carbonate $\left(\mathrm{CO}_{3}{ }^{2-}\right)$ ions. The amphiprotic bicarbonate ion $\left(\mathrm{HCO}_{3}{ }^{-}\right)$can both produce a proton and also consume a proton as in the following reactions:

$\mathrm{HCO}_{3}^{-}+\mathrm{H}^{+} \rightarrow \mathrm{H}_{2} \mathrm{CO}_{3}$

$\mathrm{HCO}_{3}^{-} \rightarrow \mathrm{H}^{+}+\mathrm{CO}_{3}^{2-}$

In our experiments, no significant alkalinity is observed in $\mathrm{pH}<4.5$. With an increase in the $\mathrm{pH}$ (4.5 to 8.3), the concentration of bicarbonate ion increases and reaches a maximum value at a $\mathrm{pH}$ of about 8.3. At this point, only the bicarbonate ions are present in the solution. With 
a further increase in $\mathrm{pH}$, the bicarbonate ions are converted to the carbonate ions. This conversion is nearly complete at a $\mathrm{pH}$ of around 10.2 with almost all of the bicarbonate ions now converted to the carbonate ions. At higher $\mathrm{pH}$ values, hydroxide ions - along with the carbonate ions - form [36]. Therefore, the inhibitive effect of the bicarbonate and carbonate ions cannot be separated from each other (unless the $\mathrm{pH}$ is different), which would then bring the effect of hydroxide ions into the picture. Several methods have been developed to determine the effect of the ionic concentrations on bicarbonate conversion. In our study, the estimation of the concentrations of the carbonate and bicarbonate ions was done via the titration method (end point) in order to determine the concentration of these species before and after the reduction process, according to the equations below [37]:

$$
\begin{aligned}
& {\left[\mathrm{HCO}_{3}^{-}\right]\left(\frac{m e q}{L}\right)=\left(\frac{A l K-K_{1} \times 10^{p H}+\frac{10^{-p H}}{\gamma}}{1+2 K_{2} \times 10^{p H}}\right)} \\
& {\left[\mathrm{CO}_{3}^{2-}\right]\left(\frac{m e q}{L}\right)=\left(\frac{A l K-K_{1} \times 10^{p H}+\frac{10^{-p H}}{\gamma}}{2+\frac{10^{-p H}}{K_{2}}}\right)} \\
& {\left[\mathrm{OH}^{-}\right]\left(\frac{m e q}{L}\right)=\left(K_{1} \times 10^{p H}\right)}
\end{aligned}
$$

Where Alk is the computed sample alkalinity, $p H$ is the initial sample $\mathrm{pH}, K_{1}$ is the acid dissociation constant of water, $K_{2}$ is the second acid dissociation constant of $\mathrm{H}_{2} \mathrm{CO}_{3}$ and $\gamma$ is the activity coefficient of $\mathrm{H}^{+}(0.914)$. The titration was carried out for the bicarbonate solution before and after the reduction reactions via the end point method. The reduction reaction was run for 3 hours by using a stainless steel electrode as the anode and the $\mathrm{Ag}_{2} \mathrm{O} / \mathrm{CNT}$ (70/30 mass) electrode as the cathode (working electrode) in a $0.5 \mathrm{M} \mathrm{NaHCO} 3$ solution. The initial $\mathrm{pH}$ is found to be 7.3 (prevalence of $\mathrm{HCO}_{3}{ }^{-}$ions) with two end points at $\mathrm{pH}$ values of 6.81 and 3.97 - indicating the generation of $\mathrm{H}_{2} \mathrm{CO}_{3}$ and the disappearance of $\mathrm{HCO}_{3}{ }^{-}$. The solution $\mathrm{pH}$ increases to 10.32 upon the completion of the reduction reaction. Also, five end points at $\mathrm{pH}$ values of $6.28,3.95,2.54,2.1$ and 1.82 are observed in the titration. There are five 
different regions on the curve for which distinctly-different calculations were done for different ions.

An increase in the solution $\mathrm{pH}$ indicates that the bicarbonate ions have been converted to the carbonate ions. Two points (i.e. 6.28 and 3.95), have been selected to generate $\mathrm{H}_{2} \mathrm{CO}_{3}$ and to eliminate the bicarbonate ions. Alk is the alkalinity of the samples and is determined as:

$A l k=1000 * V_{t} * N_{a} * C_{F} / V_{o}$

Where Alk is the alkalinity of the sample (meq/L), $V_{t}$ is the volume of titrant needed to reach the equivalence point (ml), $N_{a}$ is the normality of the acid titrant, $C_{F}$ is the acid correction factor and $V_{o}$ is the initial volume of the sample (ml).

The concentrations of the three constituents have been measured before and after reduction. The result of titration analysis shows that the $0.5 \mathrm{MNaHCO}_{3}$ solution contains the three ions: $\mathrm{OH}^{-}\left(1.9 \times 10^{-4} \mathrm{meq} / \mathrm{L}\right), \mathrm{HCO}_{3}{ }^{-}(370014 \mathrm{meq} / \mathrm{L})$ and $\mathrm{CO}_{3}{ }^{2-}(692 \mathrm{meq} / \mathrm{L})$. After the completion of the reduction reactions, the solution contains: $\mathrm{OH}^{-}(0.2089 \mathrm{meq} / \mathrm{L}), \mathrm{HCO}_{3}{ }^{-}(212895 \mathrm{meq} / \mathrm{L})$ and $\mathrm{CO}_{3}{ }^{2-}(279640 \mathrm{meq} / \mathrm{L})$. The calculated values confirm that the concentration of the carbonate ion has increased significantly while the concentration of the bicarbonate ion has dropped. The pKa value is calculated from the Henderson-Hasselbalch equation[38]:

$p K_{a}=p H+\log \left(\frac{H A}{A^{-}}\right)$

A pKa value of 10.2 is calculated for the reduction product based on the above equation. This suggests that the bicarbonate ions are converted to the carbonate and hydroxide ions. The reduction product was added to $0.5 \mathrm{M} \mathrm{CaCl}_{2}$ solution where a white precipitate was immediately formed due to the presence of calcium ions. This means that the $\mathrm{CO}_{3}{ }^{-2}$ ions have been generated in the solution after the reduction reactions. The functional groups in the liquid solutions before and after the reduction reactions as well as on the precipitated solid were determined using FTIR spectroscopy (Fig. 10). The protonated/deprotonated state shows a distinct absorption band which depends on the solution $\mathrm{pH}$. For the 
bicarbonate/carbonate solution, at $\mathrm{pH}$ values higher than 11 and less than 8 , the relative abundance of all the species did not change significantly with $\mathrm{pH}[39]$. The spectrum confirms that the samples have distinct surface functional groups. The peak at $3310 \mathrm{~cm}^{-1}$ is assigned to the stretching of the $\mathrm{OH}$ group. The FTIR studies have been done both before and after the reduction reactions. The bicarbonate ions show two distinct bands at $1635 \mathrm{~cm}^{-1}$ and $1340 \mathrm{~cm}^{-}$ ${ }^{1}$ which are assigned to the asymmetric and symmetric stretching vibrations of CO before the reduction reaction, respectively. The carbonate group also shows a broad and intense absorption band in the spectral range of $1630 \mathrm{~cm}^{-1}$ and a weak absorption band at $1390 \mathrm{~cm}^{-1}$ [40,41]. A small shift is seen in both cases between 1340 and $1390 \mathrm{~cm}^{-1}$. Shifting a band to higher or lower values depends on the bond length. If the bond length decreases the peak wave number shift to the larger values and vice versa. Changes in the bond length may occur due to a change in the electronegativity of the neighbouring atom e.g. hydrogen bonding. Two bands (871 and $1442 \mathrm{~cm}^{-1}$ ) are assigned to carbonate (out-of-plane bending) and (asymmetric stretching), which are common for both types of carbonate calcium e.g. calcite and vaterite. However, based on our FTIR spectra, the presence of vaterite is more probable [42]. Dunwell et al.(2017) studied the role of bicarbonate in the reduction reaction of $\mathrm{CO}_{2}$ on gold. They concluded that bicarbonate enhances the rate of CO production on the gold surface through rapid equilibrium between bicarbonate and the dissolved $\mathrm{CO}_{2}$ [43]. Kortlever et al. (2013) investigated electrochemical reduction of $\mathrm{CO}_{2}$ and bicarbonate on copper with a reduction peak at $-0.6 \mathrm{~V}$ (vs. RHE) - assigned to the formation of a CO on the copper surface [44]. Reduction of bicarbonate to formate via photocatalyst ZnS crystal structure was studied by Leonard et al. (2015) [45]. In addition, the teduction of bicarbonate via AgNP and Ag/MCN was studied by Arrocha-Arcos (2017) where the formation of formate was confirmed [46]. 


\section{Conclusion}

The voltammetric behaviour of an $\mathrm{Ag}_{2} \mathrm{O} / \mathrm{CNT}$ composite electrode was studied at different scan rates and electrolyte concentrations. The prepared electrodes were studied in order to identify the reactions associated with the oxidation and reduction peaks corresponding to $\mathrm{Ag}_{2} \mathrm{O}$. The reduction peak was observed at $-0.43 \mathrm{~V}$ without the presence of any oxidation peak (anodic), indicating that an irreversible reaction has taken place on the electrode surface. With an increase in the scan rate, the reduction peak density increased and shifted to negative potentials. At higher scan rates, the two peaks coalesced and only one peak appeared.

The experimental results suggest that the processes are diffusion- and adsorption-controlled. The FTIR analyses revealed an increase in the concentration of the carbonate ion, resulted from the interaction of $\mathrm{Ag}_{2} \mathrm{O} / \mathrm{CNT}$ electrode with the bicarbonate solution. The FTIR results were also successfully used in the analysis of calcium carbonate.

It is worth noting that the production of silver (as in other metal production processes) is associated with the co-generation of a substantial amount of $\mathrm{CO}_{2}$ and its subsequent release into the environment. Capturing this $\mathrm{CO}_{2}$ using the prepared electrode in this study could therefore, theoretically, mitigate part of the baseline $\mathrm{CO}_{2}$ emissions during the production of silver. However, there are specific considerations, including transportation-related emissions, which must be equally taken into account in order to fully understand the techno-economic aspects of the proposed process in this study. In addition to this, the CAPEX and OPEX of a commercial-scale process using the prepared electrode must be fully learnt in order to be able to draw a fair conclusion on not only the process efficiency, but also on the process sustainability and large-scale feasibility.

\section{Acknowledgment}


This research was supported by Rachadapisek Sompote Fund for postdoctoral Fellowship, Chulalongkorn University.

\section{References}

[1]Yong Xiang, Maocheng Yan, Yoon-Seok Choi, David Young, Srdjan Nesic, Timedependent electrochemical behavior of carbon steel in MEA-based $\mathrm{CO}_{2}$ capture process, International Journal of Greenhouse Gas Control 30 (2014) 125-132

[2] http://www.worldatlas.com/articles/biggest-contributors-to-global-warming-in-theworld.html

[3] Dimitri Mignard, Rakesh C. Barik , Arun S. Bharadwaj , Colin L. Pritchard, Marina Ragnoli ,Franco Cecconi , Hamish Miller , Lesley J. Yellowlees , Revisiting strontium-doped lanthanum cuprate perovskite for the electrochemical reduction of $\mathrm{CO}_{2}$, Journal of $\mathrm{CO} 2$ Utilization 5 (2014) 53-59

[4] Xiaowa Nie, Wenjia Luo , Michael J. Janik , Aravind Asthagiri , Reaction mechanisms of CO2 electrochemical reduction on $\mathrm{Cu}(111)$ determined with density functional theory, Journal of Catalysis 312 (2014) 108-122

[5] Takeyuki Sekimoto , Masahiro Deguchi , Satoshi Yotsuhashi , Yuka Yamada, Takekazu Masui , Akito Kuramata , Shigenobu Yamakoshi , Highly selective electrochemical reduction of $\mathrm{CO}_{2}$ to $\mathrm{HCOOH}$ on a gallium oxide cathode , Electrochemistry Communications 43 (2014) 95-97

[6] Jiani Qin, Sibo Wang, He Ren, Yidong Hou, Xinchen Wang, Photocatalytic reduction of $\mathrm{CO} 2$ by graphitic carbon nitride polymers derived from urea and barbituric acid, Applied Catalysis B: Environmental 179 (2015) 1-8

[7] Bao Pan, Shijian Luo, Wenyue Su, Xuxu Wang, Photocatalytic CO2 reduction with H2O over LaPO4 nanorods deposited with Pt cocatalyst, Applied Catalysis B: Environmental 168169 (2015) 458-464

[8] Zhihong Yuan and Mario R. Eden, Rafiqul Gani, Toward the Development and Deployment of Large-Scale Carbon Dioxide Capture and Conversion Processes, Ind. Eng. Chem. Res., 2016, 55 (12), pp 3383-3419

[9] Bhupendra Kumar, Mark Llorente, Jesse Froehlich, Tram Dang, Aaron Sathrum, Clifford P. Kubiak, Photochemical and Photoelectrochemical Reduction of CO2, Annual Review of Physical Chemistry, 63, 2012, 541-589

[10] Yin-Jia Zhang, Vijay Sethuraman, Ronald Michalsky, Andrew A. Peterson, Competition between CO2 Reduction and H2 Evolution on Transition-Metal Electrocatalysts, ACS Catalysis , 2014, 4 (10), pp 3742-3748

[11] Nianjun Yang, Siegfried R. Waldvogel, and Xin Jiang, Electrochemistry of Carbon Dioxide on Carbon Electrodes, Applied Material and interfaces, DOI: $10.1021 /$ acsami.5b09825 
[12] M.R. Gonc, alvesa, A. Gomesa, J. Condec, T.R.C. Fernandesa, T. Pardala, C.A.C. Sequeirab, J.B. Brancoc, Electrochemical conversion of CO2 to C2 hydrocarbons using different ex situ copper electrodeposits, Electrochimica Acta 102 (2013) 388-392

[13] P. Bumroongsakulsawat, G.H. Kelsall, Tinned graphite felt cathodes for scale-up of electrochemical reduction of aqueous CO2, Electrochimica Acta 159 (2015) 242-251

[14] Hoshi, N., Kato, M. \& Hori, Y. Electrochemical reduction of CO2 on single crystal electrodes of silver $\mathrm{Ag}(111), \mathrm{Ag}(100)$ and $\mathrm{Ag}(110)$. J. Electroanal. Chem. 440, 283286 (1997).

[15] Toru Hatsukade, Kendra P. Kuhl, Etosha R. Cave, David N. Abram, Thomas F. Jaramillo, Insights into the electrocatalytic reduction of CO2 on metallic silver surfaces, Phys. Chem. Chem. Phys., 2014,16, 13814-13819

[16] Cheonghee Kim, Hyo Sang Jeon, Taedaehyeong Eom, Michael Shincheon Jee, Hyungjun Kim, Cynthia M. Friend, Byoung Koun Min, Yun Jeong Hwang, Achieving Selective and Efficient Electrocatalytic Activity for $\mathrm{CO}_{2}$ Reduction Using Immobilized Silver Nanoparticles, J. Am. Chem. Soc., 2015, 137 (43), 13844-13850

[17] Amin Salehi-Khojin, Huei-Ru Molly Jhong, Brian A. Rosen, Wei Zhu, Sichao Ma, Paul J. A. Kenis, Richard I. Masel, Nanoparticle Silver Catalysts That Show Enhanced Activity for Carbon Dioxide Electrolysis, J. Phys. Chem. C 2013, 117, 1627-1632

[18] Junwei Zheng, Tianhong Lu, Therese M. Cotton, George Chumanov, Photoinduced Electrochemical Reduction of Nitrite at an Electrochemically Roughened Silver Surface, J. Phys. Chem. B 1999, 103, 6567-6572

[19] Yuki Hamasaki, Naotoshi Nakashima, Yasuro Niidome, Effects of Anions on Electrochemical Reactions of Silver Shells on Gold Nanorods, J. Phys. Chem. C, 2013, 117 (6), 2521-2530.

[20] Luisa F. Cueto-Gómez, Nora A. Garcia-Gómez, Hugo A. Mosqueda, Eduardo M. Sánchez, Electrochemical study of $\mathrm{TiO} 2$ modified with silver nanoparticles upon CO2reduction, Journal of Applied Electrochemistry , 44, 2014, 675-682

[21] Joao Henrique Lopes, Siyu Ye, Jeff T. Gostick, Jake E. Barralet, Geraldine Merle, Electrocatalytic Oxygen Reduction Performance of Silver Nanoparticle Decorated Electrochemically Exfoliated Graphene, Langmuir 2015, 31, 9718-9727

[22] Natalia García Rey, Dana D. Dlott, A Structural Transition in an Ionic Liquid Controls CO2 Electrochemical Reduction, J. Phys. Chem. C, 2015, 119 (36), 20892-20899

[23] Li Qin Zhou, Chen Ling, Michael Jones , Hongfei Jia, Selective CO2 reduction on a polycrystalline Ag electrode enhanced by anodization treatment, Chem. Commun., 2015,51, 17704-17707

[24] Mojtaba Mirzaeian, Abraham A. Ogwu, Hassan Fathinejad Jirandehi , Saule Aidarova, Zhanar Ospanova , Nathaniel Tsendzughul, Surface characteristics of silver oxide thin film 
electrodes for supercapacitor applications, Colloids and Surfaces A: Physicochem. Eng. Aspects 519 (2017) 223-230.

[25] Devthade Vidyasagar, Sachin G. Ghugal, Aditi Kulkarni, Pragya Mishra, Ashok G. Shende, Jagannath, Suresh S. Umare, Rajamma Sasikala, Silver/Silver(II) oxide (Ag/AgO) loaded graphitic carbon nitride microspheres: An effective visible light active photocatalyst for degradation of acidic dyes and bacterial inactivation, Applied Catalysis B: Environmental 221 (2018) 339-348.

[26] David F. Smith, Curtis Brown, Aging in chemically prepared divalent silver oxide electrodes for silver/zinc reserve batteries Author links open overlay panel, Journal of Power Sources, 96(2001) 121-127.

[27] Apinya Puangjan, Suwan Chaiyasith, Wipawee Taweeporngitgul, Jeerunda Keawtep, Application of functionalized multi-walled carbon nanotubes supporting cuprous oxide and silver oxide composite catalyst on copper substrate for simultaneous detection of vitamin B2, vitamin B6 and ascorbic acid, Materials Science and Engineering C 76 (2017) 383-397.

[28]Allen J. Bard, Larry R. Faulkner, Electrochemical methods Fundamentals and Applications, JOHN WILEY \& SONS, INC. New Yorke, SECOND EDITION

[29] Milad Rezaei, Seyed Hadi Tabaian,, Davoud Fatmehsari Haghshenas , A kinetic description of Pd electrodeposition under mixed control of charge transfer and diffusion, Journal of Electroanalytical Chemistry, 687,2012, 95-101

[30] E. Laviron, General expression of the linear potential sweep voltammogram in the case of diffusionless electrochemical systems, Electroanal Chem, 101 (1979), 19-28

[31] M.A. Ajeel, M.K. Aroua, W.M. A. Wan Daud , P-Benzoquinone Anodic Degradation by Carbon Black Diamond Composite Electrodes, Electrochimica Acta, Electrochimica Acta 169 (2015) 46-51.

[32] E. Zarate, P. Apell, Calculation of low-energy-electron lifetimes, PHYSICAL REVIEW B, 60.1999, 2326-2332

[33] J. Ferreira de Brito, A.A. Silva, A.J. Cavalheiro, M. V. Boldrin Zanoni, Evaluation of the Parameters Affecting the Photoelectrocatalytic Reduction of $\mathrm{CO}_{2}$ to $\mathrm{CH}_{3} \mathrm{OH}$ at $\mathrm{Cu} / \mathrm{Cu} 2 \mathrm{O}$ Electrode, Int. J. Electrochem. Sci., 9 (2014) 5961 - 5973.

[34] Yuliya Shilina, Baruch Ziv, Aviv Meir, Anjan Banerjee, Sharon Ruthstein, Shalom Luski, Doron Aurbach, Ion C. Halalay, Combined Electron Paramagnetic Resonance and Atomic Absorption Spectroscopy/Inductively Coupled Plasma Analysis As Diagnostics for Soluble Manganese Species from Mn-Based Positive Electrode Materials in Li-ion Cells, Anal. Chem., 2016, 88 (8), 4440-4447 
[35] Ole Pedersen1, Timothy D. Colmer, Kaj Sand-Jensen, Underwater photosynthesis of submerged plants - recent advances and methods, Front. Plant Sci., http://dx.doi.org/10.3389/fpls.2013.00140

[36] Narayanaru Sreekanth, Kanala Lakshminarasimha Phani, Selective reduction of CO2 to formate through bicarbonate reduction on metal electrodes: new insights gained from SG/TC mode of SECM, Chem. Commun., 2014,50, 11143-11146

[37] Frank M. Dunnivant, Environmental Laboratory Exercises for Instrumental Analysis and Environmental Chemistry, 28 JAN 2005, John Wiley \& Sons, Inc

[38] Po, Henry N.; Senozan, N. M. (2001). "Henderson-Hasselbalch Equation: Its History and Limitations". J. Chem. Educ. 78 (11): 1499-1503

[40] Maurizio Baldassarre, Andreas Barth , The carbonate/bicarbonate system as a pH indicator for infrared spectroscopy, Analyst, 2014,139, 2167-2176

[41] R.G. Gast, E.R. Landa, G.W. Meyer, The interaction of water (-FeOOH) and amorphous hydrated ferric oxide surfaces, Clays Clay Miner. 22 (1974) 31-39.

[42] M. Falk, The frequency of the $\mathrm{H}-\mathrm{O}-\mathrm{H}$ bending fundamental in solids and liquids, Spectrochim Acta, Part A 40 (1984) 43-48.

[43] Marco Dunwell, Qi Lu, Jeffrey M. Heyes, Jonathan Rosen, Jingguang G. Chen, Yushan Yan, Feng Jiao, Bingjun Xu,The Central Role of Bicarbonate in the Electrochemical Reduction of Carbon Dioxide on Gold, J. Am. Chem. Soc., 2017, 139 (10), pp 3774-3783

[44] R. Kortlever, K. H. Tan, Y. Kwon, M. T. M. Koper, Electrochemical carbon dioxide and bicarbonate reduction on copper in weakly alkaline media, Journal of Solid State Electrochemistry, 17(2013), 1843-1849.

[45] Leonard DP, Pan H, Heagy MD., Photocatalyzed Reduction of Bicarbonate to Formate: Effect of ZnS Crystal Structure and Positive Hole Scavenger, ACS. Appl. Mater. Interfaces. 7(2015)24543-9.

[46] A.A. Arrocha-Arcos, R. Cervantes-Alcalá, G.A. Huerta-Miranda, M. MirandaHernández, Electrochemical reduction of Bicarbonate to Formate with Silver Nanoparticles and Silver Nanocluster supported on Multiwalled Carbon Nanotubes, Electrochimica Acta, DOI: 10.1016/j.electacta.2017.06.147 